\title{
Aspects of Land Use in Slash and Burn Agriculture ${ }^{1}$
}

by

\section{Amitrajeet A. Batabyal ${ }^{2}$}

and

\section{Dug Man Lee ${ }^{3}$}

Batabyal acknowledges financial support from the Gosnell endowment at RIT. The usual disclaimer applies.

2

Department of Economics, Rochester Institute of Technology, 92 Lomb Memorial Drive, Rochester, NY 14623-5604, USA. Internet aabgsh@rit.edu

3

Department of Economics, Sungkyunkwan University, 53 3-ka, Myungryun-Dong, Chongro-Ku, Seoul 110-745, South Korea. Internet edml56@hanmail.net 


\title{
Aspects of Land Use in Slash and Burn Agriculture
}

\begin{abstract}
In this paper we first construct a theoretical model of land use by swidden cultivators when these cultivators can choose whether to grow a cash crop or a food/subsistence crop. Second, we study the land quality accumulation decision faced by shifting cultivators and, in the process, we show how to compute the optimal length of time during which cleared land is to be left fallow. Finally, we investigate the implications that the optimal land quality accumulation decision has for the relative price of the food crop in particular and slash and burn agriculture in general.
\end{abstract}

Keywords: Cash Crop, Fallow, Food Crop, Land Quality Accumulation, Slash and Burn Agriculture JEL Codes: Q12, Q24, D81 


\section{Aspects of Land Use in Slash and Burn Agriculture}

\section{Introduction}

Slash and burn agriculture is practiced by small farmers in many tropical developing countries. ${ }^{4}$ There are five basic stages in the slash and burn cycle. ${ }^{5}$ First, forest trees are slashed by farmers, the debris is cleared, and the cut growth is burned. The burning of the forest vegetation clears the ground for planting and releases key nutrients. As the burned vegetation decays, the organic levels in the soil rise and this enhances the soil's fertility. Second, before rains cause soil erosion and before the ash bed can be blown or leached away, planting commences. Third, with the beginning of the rainy season, normal precipitation results in rapid plant growth. Fourth, during the harvesting season, farmers protect the crop from pests and they frequently use simple implements such as finger knives to harvest the grain. Finally, the cleared parcel of forest land is left fallow. Within a couple of years, land quality improves and a closed canopy of secondary forest develops. If the cleared parcel of forest land is left fallow for a sufficiently long period of time, i.e., if the swidden cultivators accumulate land quality for a sufficiently long period of time, then nutrients will revert back to the soil and this will permit the above described slash and burn cycle to be repeated.

Researchers generally agree that slash and burn agriculture is an important and widespread phenomenon in many tropical developing countries. The disagreement among researchers concerns the desirability of this kind of agriculture. On the one hand, researchers such as Dove (1983),

4

Slash and burn agriculture is also known as swidden agriculture and as shifting cultivation. Therefore, in the rest of this paper, we shall use these three terms interchangeably.

5

For additional details on this and related issues, see Dove (1983), Peters and Neuenschwander (1988), Pearce and Warford (1993), Brown and Pearce (1994), Swinkels et al. (1997), Coomes et al. (2000), and Batabyal and Beladi (2002). 
Southgate (1990), and Pearce and Warford (1993) have argued out that slash and burn agriculture is environmentally destructive because the land clearing activities of swidden cultivators is responsible for extensive and detrimental tropical deforestation. On the other hand, a second group of researchers including Peters and Neuenschwander (1988) and Dufour (1990) have asserted that under some circumstances, slash and burn agriculture based on long fallow periods can be an ecologically and an economically sustainable practice in tropical forests.

The viability of slash and burn agriculture in the long run depends critically on the land use decisions made by small farmers. Although there now exists a fairly large empirical and case study based literature on slash and burn agriculture-see Gleave (1996), Hofstad (1997), Silva-Forsberg and Fearnside (1997), Swinkels et al. (1997), Coomes et al. (2000), Li et al. (2000), Ekeleme et al. (2000), and Udaeyo et al. (2001)—-there are virtually no theoretical studies of the land use decisions of swidden cultivators.

The theoretical paper that is closest in spirit to our paper is Batabyal and Beladi (2002). In this paper, Batabyal and Beladi construct a dynamic and stochastic model and they then use this model to set up and solve problems that tell us, inter alia, how the fallow period in slash and burn agriculture is to be optimally selected. Even though this is a useful paper, it does not model the fact that swidden cultivators typically have a choice as far as what kind of crop they would like to grow. In addition, the Batabyal and Beladi (2002) paper also does not study the land quality accumulation decision faced by shifting cultivators.

Given this state of affairs, our paper has three goals. First, we construct a theoretical model of land use by swidden cultivators when these cultivators can choose whether to grow a cash crop or a food/subsistence crop. Second, we study the land quality accumulation decision faced by shifting 
cultivators and, in the process, we complement the Batabyal and Beladi (2002) analysis by showing how to compute the optimal length of time during which the cleared land is to be left fallow. Finally, we investigate the implications that the optimal land quality accumulation decision has for the relative price of the food crop in particular and for slash and burn agriculture in general.

The rest of this paper is organized as follows. Section 2 first presents a dynamic and stochastic framework and then it uses this framework to provide a detailed analysis of the issues that we have just discussed in the previous paragraph. Section 3 concludes and offers suggestions for future research on slash and burn agriculture.

\section{A Model of Land Use in Slash and Burn Agriculture}

\subsection{Preliminaries}

The model of this section is adapted from Blanchard (1985). Consider an economy in which small farmers (or swidden cultivators) each have a parcel of cleared forest land and they can choose to grow either a cash crop or a food/subsistence crop on this land. The cash crop requires labor $L$ and high quality land $A_{h q}$ for production. In contrast, the food or subsistence crop can be grown with labor $L$ and low quality land $A_{l q}$. Let $w, s_{h q}$, and $s_{l q}$ denote the factor rewards to labor, to high quality land, and to low quality land, respectively, and let $r$ denote the interest rate. Deleterious and unpredictable environmental events such as earthquakes and volcanoes can make the small farmer's land unfit for cultivation of either the cash crop or the food crop. We account for this possibility by supposing that with instantaneous probability $q, q \in(0,1)$, the cleared land of our swidden cultivators will become unfit for cultivation. With this contingency in mind, the discount rate of our swidden cultivators is $r+q$.

Our analysis begins with an examination of the decision problem faced by an arbitrary small 
farmer (or swidden cultivator) at the completion of a specific slash and burn cycle. This corresponds to time $t=0$ and the quality of the cleared forest land at this point in time is low. Our small farmer must now decide whether to grow the cash crop or the food crop. The food crop can be grown right away because this crop requires labor-which the farmer provides-and low quality land. In contrast, the cash crop requires labor and high quality land. Hence, the cash crop cannot be grown immediately.

Now, consistent with the discussion in section 1, our small farmer can convert low quality land into high quality land by keeping this land fallow for an appropriate length of time. Put differently, this farmer can choose to accumulate land quality by keeping his or her land fallow. The reader should note two things. First, in the framework of this paper, optimally choosing the length of time during which the cleared land is to be kept fallow is equivalent to optimally accumulating land quality. Second, the purpose of investing in land quality now is to obtain higher profit from the sale

of the cash crop later. Let us now formally study an arbitrary swidden cultivator's decision problem concerning optimal land quality accumulation.

\subsection{Optimal Land Quality Accumulation}

Each swidden cultivator in our economy has a parcel of cleared land that can be left fallow, be used for food crop cultivation right away or-after fallowing-be used for cash crop cultivation. If a parcel of land is left fallow for a time interval of length $T$, then the relevant small farmer accumulates an amount of land quality equal to $V T^{\theta}, \theta \in(0,1]$, where $V$ is a shift variable and $\theta$ measures the return to fallowing land.

The key outstanding question now involves the optimal choice of $T$. To this end, suppose that our arbitrary small farmer wishes to maximize the profit from fallowing land. This profit consists of 
the earnings from cash crop cultivation less the foregone earnings from food crop cultivation. Now, the earnings from cash crop cultivation are $\int_{T}^{\infty} \exp \{-(r+q) t\} V T^{\theta} s_{h q} d t$, and the foregone earnings from food crop cultivation are $s_{l q} /(r+q) .{ }^{6}$ Therefore, to determine the optimal length of the fallow period, our small farmer solves

$$
\max _{\{T\}}\left[\int_{T}^{\infty} \exp \{-(r+q) t\} V T^{\theta} s_{h q} d t-\frac{s_{l q}}{r+q}\right]
$$

The reader will note that for there to be an interior solution to this problem, there must exist a $T$ such that the value of the integral in equation (1) exceeds the ratio $s_{l q} /(r+q)$. We assume that such an interior solution exists. Now, to determine the first order necessary condition for an optimum, we integrate, using Liebnitz's rule (see Kamien and Schwartz (1991, p. 292)) to carry out the integration.

This gives us

$$
\frac{\theta V T^{\theta-1} s_{h q}}{r+q} \exp \{-(r+q) T\}-\exp \{-(r+q) T\} V T^{\theta} s_{h q}=0 .
$$

The first order necessary condition in equation (2) can be simplified to give us the optimal value of $T$.

We get

6

In the mathematical expression for the earnings from cash crop cultivation, the reader should not interpret the upper limit of integration, which is infinity, literally. We are aware of the fact that it will not be possible for our swidden cultivator to grow the cash crop on his or her land indefinitely after one interval of fallowing. What we mean to suggest with our abstraction is that if the length of the fallow period $T$ is chosen optimally, then it will be possible for our swidden cultivator to grown the cash crop for a relatively long period of time. In addition, the reader should note that keeping the upper limit of integration infinity gives us "clean" mathematical results. Changing the upper limit of integration from infinity to something like $T+G$, where $G$ is the length of time during which the cash crop can be grown without fallowing, is unhelpful because this finite upper limit substantially complicates the mathematical analysis and ultimately leads to ambiguous results. For instance, if the upper limit of integration is $T+G$ then the optimal value of $T, T^{*}$, equals $[\theta \exp \{-(r+q) G\}-\theta] /[(r+q) \exp \{-(r+q) G\}-(r+q)]$. Toclearly see what we mean by "ambiguous results," the reader should compare this value of $T^{*}$ with the value of $T^{*}$ in equation (3). 


$$
T^{*}=\frac{\theta}{r+q}
$$

Equation (3) tells us two things that conform well with our intuition. First, as the return to fallowing land increases, i.e., as $\theta$ gets closer to one, the optimal length of the fallow period-or the optimal length of time during which land quality is accumulated-increases. Second, as our swidden cultivator's discount rate rises, i.e., as $r+q$ ) rises, it is optimal to reduce the length of time during which this cultivator's land is fallow. Inspecting equation (3), the reader will note that neither the factor reward to high quality land $s_{h q}$, nor the shift variable $V$, affect the optimal value of $T$. This is because $s_{h q}$ and $V$ multiply the term in the profit function that depends on $T$ (see equation (1)) and hence cancel out of the algebraic simplification process that leads to the derivation of equation (3). We now analyze some questions that are related to the optimal land quality accumulation issue.

\subsection{Related Questions}

What are the discounted lifetime earnings that accrue to our swidden cultivator as a result of his or her decision to accumulate land quality optimally? To answer this question, we substitute the optimal value of $T$ from equation (3) into the integral in equation (1). This gives

$$
\int_{\frac{\theta}{r+q}}^{\infty} \exp \{-(r+q) t\} V\left(\frac{\theta}{r+q}\right)^{\theta} s_{h q} d t=\exp \{-\theta\} \frac{1}{r+q} V\left(\frac{\theta}{r+q}\right)^{\theta} s_{h q} .
$$

Now, if there is to be any food crop cultivation in our economy using low quality land $A_{l q}$, then, in equilibrium, the swidden cultivator's lifetime earnings in the right-hand-side (RHS) of equation (4) must equal $s_{l q} /(r+q)$, the foregone earnings from food crop cultivation. Setting these two expressions equal to each other gives us an equation for the factor reward of high quality land relative to that of 
low quality land. That equation is

$$
\frac{s_{h q}}{s_{l q}}=\exp \{\theta\} \frac{1}{V}\left(\frac{r+q}{\theta}\right)^{\theta} .
$$

The reader will note that in our model, $V\left(T^{*}\right)^{\theta} s_{h q}$, the factor reward for optimally fallowed high quality land, must exceed $s_{l q}$, the factor reward of low quality land.

As we have discussed a little while ago, not all small farmers end up growing the cash crop. In fact, in our model, some swidden cultivators use low quality land to grow the food crop. Consequently, let us now study the impact that $\theta, V, r$, and $q$ have on $s_{l q}$, the factor reward to low quality land. Using equation (5) and then taking the derivative of $s_{l q}$ with respect to $\theta$, it is easy to see that

$$
\frac{d s_{l q}}{d \theta}=s_{l q} \log _{e}\left(\frac{\theta}{r+q}\right)>0 .
$$

In similar fashion, it can be shown that $d s_{l q} / d V>0, d s_{l q} / d r<0$, and that $d s_{l q} / d q<0$. In words, these results tell us that the factor reward to low quality land $s_{l q}$ rises with the return to fallowing parameter $\theta$ and the shift variable $V$ and it falls with increases in the interest rate $r$ and the probability $q$ of an environmentally disastrous event.

We are now in a position to state a central result about economies with slash and burn agriculture. Specifically, given $r$, the relative price of the food crop is likely to be higher in economies 
where there is high demand for keeping land fallow, ${ }^{7}$ because of high $\theta$, high $V$, or low $q$. Why? As we have already demonstrated, high $\theta$, high $V$, or low $q$ means that the factor reward for low quality land $s_{l q}$ is high. In turn, because $r$ is given, a high $s_{l q}$ can be expected to exert an upward pressure on the relative price of the food crop. This concludes our discussion of land use in slash and burn agriculture.

\section{Conclusions}

We addressed three issues in this paper that, to the best of our knowledge, have not been addressed previously in the theoretical literature on slash and burn agriculture. First, we constructed a theoretical model of land use by shifting cultivators when these cultivators can choose whether to grow a cash crop or a food/subsistence crop. Second, we studied the land quality accumulation decision faced by swidden cultivators and, in the process, we showed how to compute the optimal length of time during which the cleared land is to be left fallow. Finally, we investigated the implications that the optimal land quality accumulation decision has for the factor reward to low quality land and then we showed that given $r$, the relative price of the food crop is likely to be higher in economies where there is high demand for keeping land fallow.

The analysis contained in this paper can be extended in a number of different directions. In what follows, we suggest two avenues for research on the subject of slash and burn agriculture. First, in the model of this paper, keeping land fallow is a prerequisite for cultivating only the cash crop. As such, it would be useful to analyze a model in which the cultivation of the cash crop and the food crop requires that land be fallowed for a certain length of time. Second, it is well known that different 
crops affect land quality - and hence the length of the fallow period-in dissimilar ways. Consequently, it would be instructive to analyze a scenario in which small farmers are able to choose between cash crops that have differential impacts on land quality. Studies that incorporate these aspects of the problem into the analysis will provide additional insights into the connections between the land quality accumulation decision and the successful practice of slash and burn agriculture. 


\section{References}

Batabyal, A.A., and Beladi, H. 2002. Swidden Agriculture in Developing Countries. Downloadable at http://papers.ssrn.com/author=61439 Forthcoming, Review of Development Economics.

Blanchard, O.J. 1985. Debt, Deficits, and Finite Horizons, Journal of Political Economy, 93, 223247.

Brown, K., and Pearce, D.W., Eds. 1994. The Causes of Tropical Deforestation. University of British Columbia Press, Vancouver, British Columbia.

Coomes, O.T., Grimard, F., and Burt, G.J. 2000. Tropical Forests and Shifting Cultivation: Secondary Forest Fallow Dynamics Among Traditional Farmers of the Peruvian Amazon, Ecological Economics, 32, 109-124.

Dove, M.R. 1983. Theories of Swidden Agriculture and the Political Economy of Ignorance, Agroforestry Systems, 1, 85-99.

Dufour, D.L. 1990. Use of Tropical Rainforests by Native Amazonians, BioScience, 40, 652-659.

Ekeleme, F., Akobundu, I.O., Isichei, A.O., and Chikoye, D. 2000. Influence of Fallow Type and Land-Use Intensity on Weed Seed Rain in a Forest/Savanna Transition Zone, Weed Science, 48, 604-612.

Gleave, M.B. 1996. The Length of the Fallow Period in Tropical Fallow Farming Systems: A Discussion With Evidence from Sierra Leone, Geographical Journal, 162, 14-24.

Hofstad, O. 1997. Degradation Processes in Tanzanian Woodlands, Forum for Development Studies, 0, 95-115.

Kamien, M.I., and Schwartz, N.L. 1991. Dynamic Optimization, $2^{\text {nd }}$ edition. North-Holland, Amsterdam, The Netherlands. 
Li, F., Zhao, S., and Geballe, G.T. 2000. Water Use Patterns and Agronomic Performance for Some Cropping Systems With and Without Fallow Crops in a Semi-Arid Environment of Northwest China, Agriculture, Ecosystems, and Environment, 79, 129-142.

Pearce, D.W., and Warford, J.J. 1993. World Without End: Economics, Environment, and Sustainable Development. Oxford University Press, Oxford, UK.

Peters, W.J., and Neuenschwander, L.F. 1988. Slash and Burn: Farming in the Third World Forest. University of Idaho Press, Moscow, Idaho.

Silva-Forsberg, M.C., and Fearnside, P.M. 1997. Brazilian Amazonian Caboclo Agriculture: Effect of Fallow Period on Maize Yield, Forest Ecology and Management, 97, 283-291.

Southgate, D. 1990. The Causes of Land Degradation along Spontaneously Expanding Agricultural Frontiers in the Third World, Land Economics, 66, 93-101.

Swinkels, R.A., Franzel, S., Shepherd, K.D., Ohlsson, E., and Ndufa, J.K. 1997. The Economics of Short Rotation Improved Fallows: Evidence From Areas of High Population Density in Western Kenya, Agricultural Systems, 55, 99-121.

Udaeyo, N.U., Umoh, G.S., and Ekpe, E.O. 2001. Farming Systems in Southeastern Nigeria: Implications for Sustainable Agricultural Production, Journal of Sustainable Agriculture, 17, 75-89. 